\title{
Narrar o trauma nas diásporas: Metáforas da doença nas literaturas de autoria feminina do Zimbábue
}

\author{
Larissa da Silva Lisboa Souza iD 0000-0001-5922-8710 \\ Universidade de São Paulo, Departamento de Letras Clássicas e Vernáculas, Estudos \\ Comparados de Literaturas de Língua Portuguesa, São Paulo, SP, Brasil. \\ 05508-010-posdlcv@usp.br
}

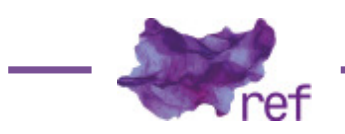

Resumo: O artigo tem como objetivo refletir sobre o processo de desterritorialização dos sujeitos africanos que vivenciam a diáspora, a partir de três textos de autoria feminina da República do Zimbábue: Nervous Conditions (DANGAREMBGA, 1988), Zenzele, uma carta para minha filha (MARAIRE, 1996) e Precisamos de Novos Nomes (BULAWAYO, 2014). A discussão terá como foco a análise de algumas personagens dos livros e como suas experiências resultaram em traumas, tanto psicológicos quanto físicos, na observação das diferentes perspectivas de superação.

Palavras-chave: literatura; Zimbábue; trauma; diáspora.

Narrating the Trauma in The Diasporas: Metaphors of The Disease in The Literature of Female Authorship in Zimbabwe

Abstract: This paper aims to reflect on the process of deterritorialization of African subjects who experienced the diaspora, choosing three texts of female authorship from the Republic of Zimbabwe, Nervous Conditions (DANGAREMBGA, 1988), Zenzele: uma carta para minha filha (MARAIRE, 1996) and Precisamos de Novos Nomes (BULAWAYO, 2014). The discussion will focus on the analysis of some characters in the books and how their experiences resulted in traumas, both psychological and physical, in observing the different perspectives of overcoming.

Keywords: Literature; Zimbabwe; Trauma; Diaspora.

As reflexões que compõem este artigo partem de minha leitura dos livros de Susan Sontag: A Doença como metáfora (1984) e A AIDS como metáfora (1989). O sofrimento degradante dos sujeitos discutidos nos ensaios é não apenas resultado do diagnóstico de uma doença, como também uma metáfora das relações históricas, sociais e culturais das sociedades.

A doença como castigo, a exemplo da tuberculose, no século XIX, resultado de uma vida leviana; o câncer, no século XX, reflexo de contenções do prazer, ou mesmo a AIDS, como decorrência da promiscuidade homossexual, discutida e tensionada por Sontag, forma um caminho reflexivo para as minhas leituras dos textos contemporâneos de autoria feminina do Zimbábue, em que a doença está presente em muitas narrativas, através das experiências da diáspora que as personagens vivenciam.

Outro ponto relevante das leituras de Sontag discute o imaginário coletivo criado sobre a origem de muitas doenças devastadoras, muitas delas vindas "de fora", um lugar outro, estrangeiro. Exemplificando por meio da peste bubônica, a autora afirma que a doença era considerada uma espécie de invasão (Susan SONTAG, 1989, p. 58), como parte da imagem secular do continente europeu culturalmente privilegiado, ou seja, não produtor de doenças. E ainda ressalta a indiferença das comunidades europeias frente às inúmeras devastações que produziram nesses outros lugares, introduzindo suas doenças - desde as grandes navegações até os processos de colonização nos séculos XIX e XX. 
Nesse sentido, gostaria de refletir sobre os espaços imperialistas (Europa e Estados Unidos) enquanto produtores de doenças, a partir da discussão de alguns textos de autoria feminina do Zimbábue que tratam das inúmeras impossibilidades aos africanos nos seus espaços de origem, resultando em traumas pelos processos de diásporas.

A palavra diáspora, de origem grega que significa "dispersão", designou inicialmente o trânsito do povo judeu pelo mundo. A primeira metade do século XX é marcada por duas grandes guerras na Europa, logo, os holofotes históricos voltaram-se completamente para este território, 0 que inclui o trânsito forçado de milhões de judeus aos campos de concentração nazistas na Alemanha, durante a Segunda Guerra, silenciando, dessa forma, outros espaços e povos.

Durante toda a segunda metade do século XX e início das primeiras décadas do XXI, uma quantidade significativa de obras artísticas que tratam a diáspora do povo judeu surgiu como forma de narrar o trauma da guerra (Márcio SELIGMANN-SILVA, 2008). Contudo, é notório que essas memórias "de um passado que não passa" (SELIGMANN-SILVA, 2008, p. 69) fazem parte de uma história única, ' visto que, em meio a tantos filmes hollywoodianos e livros sobre o nazismo, quais são as obras artísticas que discutem o holocausto no Congo (atual Zaire) pelo Rei belga Leopoldo II, entre 1890 e 1910, com 8 milhões de africanos mortos, ou mesmo os mais de 300 anos de escravidão e seus conflitos no pós-abolição, durante todo o século XX?

É possível refletir sobre a diáspora para além do judaísmo. Particularmente sobre os povos africanos, esses estudos designam dois tipos de trânsitos: através da dispersão pelo mar Mediterrâneo, durante a antiguidade; posteriormente, pelo mar Vermelho e pelo oceano Índico, na ldade Média e durante as rotas de navegação pelo atlântico, a partir do século XVI, com o início do tráfico negreiro, com dispersões para os Estados Unidos e a América Latina (James HARRIS, 2010).

Consciente do perigo de uma história única, tenho como objetivo trazer à discussão o trauma nos processos de diásporas africanas, através do segundo trânsito diaspórico, resultado da colonização europeia, o que também inclui os Estados Unidos, na análise de três textos literários de autoria feminina do Zimbábue: o primeiro, Nervous Conditions (Tsitsi DANGAREMBGA, 1988); o segundo, Zenzele: Uma carta para minha filha (J. Nozipo MARAIRE, 1996) e o terceiro, Precisamos de Novos Nomes (NoViolet BULAWAYO, 2014). As duas primeiras obras artísticas rememoram o período colonial do país, na passagem para a independência, e a terceira trata tanto do primeiro período, como do pós-independência e as primeiras décadas do século XXI.

Os textos escolhidos espelham o contexto do país nas décadas de transição, discutindo as complexas relações entre brancos e negros. As personagens principais são mulheres que trazem não apenas as suas histórias individuais, como também as vivências de sujeitos próximos, a exemplo de seus familiares. É nesse contexto que as três obras discutem algumas experiências da diáspora de forma traumática, surgindo, ao longo das narrativas, certas doenças.

Na observação dos traumas dos processos de diáspora, que resultaram em diferentes conflitos para as personagens, serão analisadas: a afasia, a alienação cultural e a loucura, na tentativa de compreender o que essas metáforas representariam na construção das identidades desses sujeitos.

\section{Traumas do/no processo diaspórico: a doença como metáfora das velhas e novas identidades}

Os estudos diaspóricos na contemporaneidade ${ }^{2}$ estão relacionados com as questões de identidade cultural e suas complexidades. Para Stuart HALL (2003),

[...] presume-se que a identidade cultural seja fixada no nascimento, seja parte da natureza, impressa através do parentesco e da linhagem dos genes, seja constituída de nosso eu mais interior [...] A pobreza, o subdesenvolvimento, a falta de oportunidades - os legados do Império em toda parte - podem forçar as pessoas a migrar, o que causa o espalhamento - a dispersão (p. 28).

O autor atenta para que esse processo não seja estudado apenas a partir de uma visão binária (eu e o outro), sem compreender suas nuances e hibridismos, o que poderia ocasionar uma análise sem aprofundamento. Dessa maneira, a diáspora deve ser observada como uma "subversão dos modelos culturais tradicionais orientados para a nação" (HALL, 2003, p. 36).

Enquanto pensadores como Stuart Hall refletem sobre a diáspora a partir de uma visão póscolonial, ou seja, não como um fenômeno "apocalíptico" das culturas, mas sim enquanto uma reinvenção "integrada" ${ }^{3}$ de suas identidades, os textos africanos de autoria feminina neste artigo

\footnotetext{
${ }^{1}$ Faço referência ao vídeo da nigeriana Chimamanda Adichie, "O perigo da histórica única". Disponível em https:// www.ted.com/talks/chimamanda_adichie_the_danger_of_a_single_story/transcript?language=pt-br. Acesso em 12/ $01 / 2018$.

${ }^{2}$ Compreendo o contemporâneo a partir das reflexões de Agamben (2009). Logo, pensá-lo nos estudos africanos seria discorrer sobre um tempo de disjunção, deslocamento e certo anacronismo resultante dos processos de independência que não trouxeram, ao longo do século XX, reais benesses para as sociedades.

${ }^{3}$ Faço referência ao livro Apocalípticos e Integrados, de Umberto Eco (1970).
} 
se constroem a partir dos conflitos dos sujeitos que experienciam esses trânsitos, tanto na tentativa de perpetuação de suas identidades como na adaptação às novas, em outros espaços e contextos. Essa discussão faz com que as considerações do psiquiatra, filósofo e ensaísta da Martinica Frantz FANON (1968) ainda sejam atuais. Em Os condenados da terra, Fanon traz as suas experiências no campo da psiquiatria como contribuição às reflexões sobre os traumas dos sujeitos africanos pelos processos de colonização.

Para o autor, "o mundo colonizado é um mundo cindido em dois" (FANON, 1968, p. 27), uma afirmação que levanta questionamentos sobre os espaços africanos colonizados por europeus que se beneficiaram de inúmeros privilégios, enquanto os africanos viviam às margens, condenados em sua própria terra.

O espaço colonial mostra-se como um lugar de intensos conflitos, pelo apartheid imposto aos negros. Na dicotomia colono-colonizado, Fanon (1968) observa o espaço colonial:

A cidade do colono é uma cidade sólida [...] É uma cidade iluminada, asfaltada, onde os caixotes de lixo regurgitam de sobras desconhecidas, jamais vistas, nem mesmo sondadas. Os pés do colono nunca estão à mostra [...] enquanto que as ruas de sua cidade são limpas, lisas, sem buracos, sem seixos [...] a cidade do colono é uma cidade de brancos, de estrangeiros [...] A cidade do colonizado [...] a cidade negra, a medina, a reserva, é um lugar mal afamado, povoado de homens mal afamados [...] A cidade do colonizado é uma cidade faminta [...] acocorada, uma cidade ajoelhada, uma cidade acuada (p. 28-29).

É justamente o que o leitor observa no livro de NoViolet Bulawayo, Precisamos de Novos Nomes, com a primeira publicação em 2013. O roubo de goiabas no bairro branco Budapeste, pelas crianças do bairro negro Paraíso, na cidade de Bulawayo, antiga Rodésia (atual Zimbábue), é um interessante diálogo com as afirmações de Fanon. A escolha do nome bíblico representa ironicamente um espaço sem nenhuma condição aos seus moradores, na realidade, um lugar para não se permanecer:

[...] E quando falam assim Pa-ra-í-so, sabemos que é um lugar do qual vamos embora, como na bíblia, quando as pessoas deixaram aquele lugar horrível e aquele velho de barba comprida feito o Papai Noel bateu na estrada com seu cajado e, em seguida, havia um rio atrás deles (BULAWAYO, 2014, p. 68).

As goiabas, assim como as ruas limpas e organizadas do bairro dos brancos, representam o oposto dos lugares sem comida, com lixo e barracos de zinco das moradas do Paraíso. Diálogo também possível com o livro de J. Nozipo Maraire, Zenzele: Uma carta para minha filha, publicado em 1996, visto que o espaço rural em que vivia a narradora durante a infância está em oposição ao urbanizado, majoritariamente de colonos brancos.

Se as goiabas eram a representação do desejo do colonizado em possuir algo do colono no primeiro livro, o vestido seria o objeto de cobiça do segundo, na representação da impossibilidade aos negros em serem consumidores, ainda que tivessem poder aquisitivo para tanto: "- Aderi aos guerrilheiros porque queria um vestido. Só isso. Aos 15 anos, eu simplesmente queria um vestido cor-de-rosa com flores alvas" (MARAIRE, 1996, p. 192).

No livro de Tsitsi Dangarembga, Nervous Conditions, publicado em 1988, a ânsia do colonizado era o acesso à educação e, no caso da protagonista Tambudzai, algo praticamente impossível, pois os poucos negros que estudavam eram homens.

Nessa ambientação de oposições é que se inserem as três obras. Nervous Conditions e Precisamos de Novos Nomes. Trata-se de romances de formação que trazem as experiências das personagens desde a infância até a fase adulta, através dos processos de diáspora. Já Zenzele: Uma carta para minha filha configura-se num relato para que os mais jovens, aqueles que vivenciam a diáspora, possam conhecer a história de seu país, e que os mesmos não se esqueçam de suas identidades enquanto africanos.

O livro Nervous Conditions talvez seja a obra que mais represente a "patologia mental produzida diretamente pela opressão" (FANON, 1968, p. 212), por um motivo particular, a data de sua publicação. A obra tem como primeira edição o ano de 1988, apenas oito anos após a independência do Zimbábue. ${ }^{4}$ Neste contexto, as questões coloniais ainda se faziam muito presentes e as dicotomias entre colonos e colonizados eram mais latentes. Diferença que será interessante observar na discussão mais adiante sobre o livro Precisamos de Novos Nomes.

Segundo M. Keith BOOKER (1998), a obra de Tsitsi Dangarembga vem de uma tradição literária africana que discute o colonialismo através das experiências da infância, a exemplo de escritores como Camara Laye, Wole Soyinka e George Lamming. Nervous Conditions traz a estória de Tambudzai, na rememoração de sua vida durante um período determinado, o fim da infância e o início da fase adulta. Com uma forte discussão sobre a mulher em um complexo contexto, tanto

\footnotetext{
${ }^{4}$ A Independência da República do Zimbábue (antiga Rodésia) foi declarada em 1965, entretanto, só foi reconhecida
} em 1980. 
representado pelo patriarcado europeu, como pela cultura tradicional shona, o livro inicia com a morte de Nhamo, irmão da protagonista e narradora, acontecimento fundamental para que a mesma tenha direito de estudar e, assim, entrar em contato com outras culturas e identidades, durante o período colonial.

Nos primeiros capítulos, Tambudzai relembra as experiências de seu irmão Nhamo na escola e as mudanças do mesmo, visto que, para que este estudasse, era necessário sair da aldeia rural onde viviam, para os espaços mais urbanizados. Nhamo, através de sua diáspora endógena, teve a oportunidade de conhecer e ter contatos com diferentes realidades, ampliando, dessa forma, a sua relação com o mundo.

Com o tempo, o rapaz passa a retornar menos para a casa. E, logo, muitas mudanças acontecem. Segundo a narradora, transformações que são reflexos da relação do irmão com o novo mundo,

Nhamo was forced once a year to return to his squalid homestead, where he washed in cold water in an enamel basin or a flowing river, not in a bathtub with taps gushing hot water and cold; where he ate sadza regularly with his fingers and meat hardly at all, never with a knife and fork (DANGAREMBGA, 1998, p. 6). ${ }^{5}$

Cada vez menos sociável, Nhamo começa a perder a comunicabilidade com a sua comunidade de origem, o que inclui Tambudzai e sua família. E, em um dos momentos de retorno à aldeia, o mesmo passa a não falar mais a sua língua materna, o shona.

Then when Nhamo came home at the end of his first year with Babamukuru, you could see he too was no longer the same person [...] All this was good, but there was one terrible change. He had forgotten how to speak Shona. A few words escaped haltingly, ungrammatically and strangely accented when he spoke to my mother, but he did not speak to her very often any more (DANGAREMBGA, 1998, p. 52). ${ }^{6}$

No diálogo entre os moradores da aldeia os conflitos se intensificam porque Nhamo responde sempre em inglês, na representação da incomunicabilidade entre eles. Enquanto a narradora compreendia que, cada vez mais o irmão ficava no outro espaço, mais distante dos seus ele se tornava. Seu pai entendia de forma completamente diferente, que o menino estava mais educado.

É interessante observar que a incomunicabilidade da personagem, para as mulheres da aldeia, como Tambudzai e sua mãe, representava um problema, um conflito com a sua identidade de grupo: "[...] you and your education have killed my son!" (DANGAREMBGA, 1998, p. 54), ${ }^{7}$ enquanto que, para os homens, como o pai de Nhamo, isso se relacionava com uma mudança positiva, em que o protagonismo da língua inglesa refletia melhores condições de vida.

O problema de Nhamo é parecido com a construção de outra personagem, no livro de J. Nozipo Maraire, Zenzele: Uma carta para minha filha, publicado em 1996. A carta de uma mãe amorosa à filha, que parte para a Europa, traz em sua narrativa as experiências de vida de uma mulher que transitou por dois momentos históricos do país, o período colonial e o pós-independência.

Na lembrança de um dos diálogos entre as duas mulheres, a filha, deslumbrada com o novo mundo, o espaço da diáspora, questiona a mãe: "- Mamãe, você nunca quis estudar em Londres ou viver uns tempos em Paris?". E, como resposta: "- Para falar a verdade, o mundo ocidental é encantador [...] nele é fácil perder-se" (MARAIRE, p. 1996, p. 65).

A partir dessa rememoração introdutória, a narradora Zenzele discute a trajetória de Mukoma Byron, seu primo que fora estudar medicina em Oxford, na Inglaterra, graças a uma bolsa de estudos da Igreja Metodista Umtali Leste.

Byron, chamado de Watts na aldeia, era considerado um garoto brilhante. Além de muito inteligente e dedicado, tanto na lavoura como nos estudos, era solidário e afetuoso com todos. Por isso, a comunidade comemorou a conquista do jovem, ajudando-o a levantar dinheiro para se manter na Europa.

Neste momento da narrativa, Zenzele faz um adendo: "[...] Nem preciso contar que falávamos sempre em chona, ${ }^{8}$ o inglês era complicado para nós, dava a impressão de que havíamos engolido uma bebida gasosa e todas as bolhas nos saíam depois pelo nariz" (MARAIRE, 1996, p. 67), como um prelúdio para a discussão sobre a linguagem que viria na sequência.

\footnotetext{
${ }^{5}$ Tradução: Nhamo fora forçado, uma vez ao ano, a retornar à sua miserável casa, onde se banha na água fria de uma bacia esmaltada ou nas águas de um rio, não em uma banheira com torneiras que jorram água quente e fria; onde ele come sadza regularmente com as mãos, dificilmente come carne, e nunca com garfo e faca. Observação: Não existe tradução para a língua portuguesa do livro Nervous Conditions. Os excertos traduzidos são de minha responsabilidade.

${ }^{6}$ Tradução: Quando Nhamo voltou para casa no final de seu primeiro ano com Babamukuru, você poderia ver que ele já não era o mesmo [...] Tudo ia bem, mas houve uma mudança terrível. Ele tinha esquecido como falava a língua Shona. Poucas palavras escapavam, hesitantemente, sem gramática e estranhamente acentuadas quando ele falava com a mãe, mas ele já não fala mais com tanta frequência com ela.

${ }^{7}$ Tradução: Você e sua educação têm matado meu filho!

${ }^{8} \mathrm{~A}$ tradução da palavra está grafada com "c" e não "s".
} 
Dessa maneira, Mukoma Byron vai para a Inglaterra, como uma promessa para a aldeia de um futuro médico. A personagem, assim, seria um herói colonizado que se apropriaria do conhecimento do colonizador para salvar os seus. Nos primeiros anos, Byron mantém a palavra. Porém, o contato com os seus torna-se cada vez menor, visto que as cartas, com o tempo, eram menos frequentes.

Referindo-se à Zenzele como "Shiri", Byron questionava: “- Shiri, você já pensou no que significa, afinal, ser africana?" (MARAIRE, 1996, p. 69). Respostas que Zenzele não tinha, visto que esses não eram questionamentos que a menina fazia, afinal, a mesma vivenciava o seu espaço, localizada na sua comunidade. Mas, para Byron, vivendo na Europa, essa questão fazia muito sentido.

Segundo Fanon (1968), a experiência da opressão colonialista resulta neste tipo de questionamento: "Por ser uma negação sistemática do outro, uma decisão furiosa de recusar ao outro qualquer atributo de humanidade, o colonialismo compele o povo dominado a se interrogar constantemente: 'Quem sou eu na realidade?'” (p. 212).

Byron, então, retorna ao Zimbábue já livre, depois de 15 anos. E logo Zenzele percebe as mudanças, a exemplo do nome do país, que Byron ainda fazia questão de denominar "Rodésia", a nomenclatura colonial. Como Nhamo, Byron também se comportava de modo estrangeiro, como comer sadza, uma comida típica do Zimbábue, com garfo e faca, ao invés de usar as mãos, e a recusa à língua shona, comunicando-se apenas em inglês. Quando retorna à aldeia para visitar sua mãe que está doente, Byron diz à Zenzele:

Por favor, traduza. Diga a ela que não sei mais falar chona, isso foi há muito tempo [...] Por favor, diga que não posso cuidar dela porque não sou médico, jamais concluí a faculdade. Não poderia... Diga que agora trabalho em Londres e fiz dessa cidade meu lar. Sinto muito (MARAIRE, 1996, p. 80).

Assim como Nhamo e Byron, muitas outras personagens em obras literárias africanas póscoloniais são retratadas de forma semelhante, como parte de uma reflexão consciente sobre os processos de colonização, descolonização e seus traumas. No conto House of Hunger (primeira publicação em 1978), um dos maiores textos da literatura zimbabuana, Dambudzo MARECHERA (1993) narra de forma lírica o sofrimento no processo diaspórico, em que o sujeito africano, na consciência de seu não pertencimento aos novos espaços, vivencia um processo de alienação cultural que resulta na loucura.

Percebe-se, nesse sentido, que não apenas a partida e a experiência na diáspora, como também o retorno ao espaço de origem fazem parte das complexidades dessas vivências. A afasia de Nhamo e Byron representa, assim, uma metáfora sobre a condição do sujeito colonial nas diásporas e, como resultado, a alienação cultural. É apenas nesses novos espaços que esses sujeitos passam a questionar as suas identidades, porque nesses lugares outros é possível indagar: como (re)construir essas subjetividades? Desse modo, a identidade torna-se figura fulcral de questionamentos e contestações, muitas vezes, como no caso das duas personagens, negando o passado e suas identidades primeiras.

A língua, representação maior da comunicabilidade entre as pessoas, é a porta de acesso a esses novos territórios; o inglês, o acesso ao mundo colonial, ao outro; o shona, ao passado, à memória que se perde. Portanto, tanto Nhamo como Byron constroem as suas novas identidades com a língua do colonizador como passaporte para o acesso ao mundo que desejam. Negar a língua shona é a única maneira que encontram para refazer as suas subjetividades. $E$, assim, a afasia surge como resultado da complexidade das experiências ambíguas do mundo cindido em dois, como elucida Fanon.

NoViolet Bulawayo, em Precisamos de Novos Nomes (2014), também levanta essas discussões, mas a partir de outro ponto de vista. Darling, a protagonista e narradora da estória, traz as suas memórias sobre a infância no bairro periférico "Paraíso", durante a colonização do Zimbábue, e seu processo diaspórico para os Estados Unidos, já na adolescência.

Diferente dos outros dois livros, Darling rememora passagens nostálgicas, de um tempo de muitas dificuldades aos negros, mas do qual a amizade, o afeto e a solidariedade são as lembranças mais latentes; sem, contudo, construir uma relação de oposição (o espaço originário nostálgico e o espaço de diáspora conflitivo). A personagem vai se adaptando ao novo território estadunidense, no acesso aos bens de consumo, como a alimentação, lazer em shoppings, objetos eletrônicos, mas sempre com uma consciência de seu lugar marginal no mundo globalizado:

Mas quando chegamos à América e vimos toda aquela comida, prendemos a respiração e pensamos, espere, deve haver um Deus [...] comemos feito porcos, feito lobos, feito dignitários. Comemos feito abutres, feito cachorros de rua, feito monstros; comemos feito reis. Comemos por toda a nossa fome passada, pelos nossos pais e irmãos e parentes e amigos que ainda estão lá no nosso país (BULAWAYO, 2013, p. 210). 
Darling, na verdade, pouco difere de Nhamo e Mukoma Byron no processo de alienação cultural. Contudo, enquanto as escritoras Tsitsi Dangarembga e J. Nozipo Maraire têm um posicionamento mais radical quanto às mudanças que são resultado do processo diaspórico, reflexo de um tempo histórico em que grande parte dos textos literários estava concatenada às discussões políticas dos processos de independências e ao imaginário nacional, NoViolet Bulawayo faz parte de uma geração de escritores de outro período, em que as diásporas são pensadas enquanto movimentos híbridos, através do não apagamento das identidades que esses sujeitos carregam.

Dessa maneira, as reflexões de Stuart Hall são mais bem compreendidas com este último livro, pelo discurso mais contemporâneo sobre a diáspora africana e seus processos de desterritorialização. A identidade de Darling é resultado do hibridismo cultural do mundo globalizado, trazendo a sua experiência de mundo, porém, rompendo as amarras dicotômicas.

[...] estou sendo obrigada a ouvir aquela canção idiota da Rihanna que todo mundo na escola ouvia como se fosse um hino ou algo do tipo [...] Sei que o namorado maluco deu uma surra nela, mas acho que ela não precisa aparecer em todo o canto, como se o seu rosto fosse uma crise humanitária, como se fosse o Sudão ou coisa do tipo (BULAWAYO, 2013, p. 193).

Darling, como qualquer garota "americana", ouve as músicas da cantora norte-americana Rihanna. A particularidade da personagem se dá, todavia, pelas suas vivências no espaço africano. O incômodo é parte de sua identidade cultural, carregada de histórias e experiências, ampliando, assim, a sua compreensão sobre um simples acontecimento cotidiano. Mas, obviamente, não deixando de ouvir a estrela pop.

É esta a particularidade da obra que a diferencia dos outros textos analisados. A doença de Darling é a mesma de Nhamo e Byron, a alienação cultural, a busca pelo consumo, o conforto efêmero que o capitalismo, através das grandes potências, oferece aos imigrantes vindos dos espaços subdesenvolvidos do globo, à margem nas sociedades americanas e europeias. Porém, diferente dos livros anteriores, em Precisamos de novos nomes o consumo representa um desejo que a sacia e ele está integrado no seu processo identitário. Dessa maneira, as experiências na diáspora são narradas de forma menos dolorosa do que nos textos de Dangarembga e Maraire, ainda que Stuart Hall (2003) reitere: "como outros processos globalizantes, a globalização cultural é desterritorializante em seus efeitos" (p. 36).

Logo, a doença também se manifesta no romance de NoViolet Bulawayo. Enquanto a adolescente Darling está aberta ao novo, acontece o oposto com Tshaka Zulu, um familiar mais velho, que vive em uma casa de repouso nos Estados Unidos.

Considerado como louco, Tshaka Zulu chega à diáspora negando completamente o novo espaço em que se insere. Na procura desesperada por suas memórias, constrói em seu quarto uma tentativa de resgate de sua identidade africana:

Estar no quarto de Tshaka Zulu é como estar num museu de memórias ou coisa do tipo - as paredes do porão estão sufocando com as coisas que tem ali: recortes de jornal de Nelson Mandela, de quando ele saiu da prisão e tudo mais, fotos do Presidente do nosso país, quando ele se tornou presidente e ainda tinha cabelo, uma foto de Kwane Nkrumah, de Kofi Annan, uma foto grande de Desmond Tutu, fotos de Miriam Makeba, Brenda Fassie, Hugh Masekela, Lucky Dube, um recorte de jornal de Credo Mutwa, fotos emolduradas de Bébé Manga, Leleti Khumalo, Wangari Maathai e assim por diante (BULAWAYO, 2013, p. 207).

A doença dessa personagem no livro de Bulawayo é uma enfermidade oposta à alienação cultural de Nhamo e Byron. Enquanto a afasia dos primeiros figura como metáfora do apagamento do passado, a loucura de Tshaka Zulu representa o apagamento do presente. Logo, não há presente em outro espaço que não seja aquele do qual ele faz parte. A personagem, então, nega o hibridismo, a identidade cultural nos processos de diáspora e busca incessantemente o retorno às suas identidades, ao seu lugar, ainda que seja em um quarto fechado de uma clínica psiquiátrica, apegando-se ao passado através de recortes de jornal, textos, fotografias e referências próprias.

Tshaka Zulu está no livro de NoViolet Bulawayo não por acaso. A sua loucura pode ser interpretada como uma crítica à essência identitária africana, que na realidade já não existe em um mundo que não é mais "cindido em dois", como trouxe Fanon, mas sim globalizado. Ele é o velho, o antigo, a antiga crítica ao colonialismo, a negação total de qualquer contato com o novo, enquanto Darling é o híbrido, o próprio processo de desterritorialização, a oportunidade de experienciar novas histórias sem tantos sofrimentos, ainda que de forma crítica e consciente.

Todavia, independente do tempo histórico, algo ainda é perpetuado. A diáspora africana traz em seus trânsitos sujeitos para um novo mundo de impossibilidades. Afinal, os africanos continuam à margem dessas sociedades, os imigrantes ilegais não podem mais retornar aos seus territórios de origem, ocupando, assim, os bairros periféricos das grandes cidades, como Darling e sua família: "Nós nunca seríamos aquilo que queríamos ser: médicos, advogados, professores, engenheiros" (BULAWAYO, 2013, p. 212). 
A morte de Tshaka Zulu não poderia ser mais bem arquitetada na obra; a não compreensão de sua "loucura" pelo tratamento psiquiátrico ocidental e a violência policial, algo infelizmente comum nos bairros negros estadunidenses.

Portanto, concluo que as três obras artísticas discutidas trazem os traumas como resultado de um processo ainda complexo das diásporas, em que, num mundo cindido em dois, ou mesmo no novo mundo globalizado, os africanos ainda estão às margens dos Impérios. ${ }^{9}$

\section{Referências}

AGAMBEN, Giorgio. O que é o contemporâneo? E outros ensaios. Tradução de Vinícius Nicastro Honesko. Chapecó: Argos, 2009.

BOOKER, M. Keith. "Tsitsi Dangarembga: Nervous Conditions". In: BOOKER, M. Keith. The African Novel in English. An Introduction. Oxford: University of Arkansas, 1998.

BULAWAYO, NoViolet. Precisamos de Novos Nomes. Tradução de Adriana Lisboa. São Paulo: Globo, 2014.

DANGAREMBGA, Tsitsi. Nervous Conditions. United Kingdom: Women's Press, 1988.

FANON, Frantz. Os condenados da Terra. Tradução de José Laurênio de Melo. Rio de Janeiro: Civilização Brasileira, 1968.

HALL, Stuart. Da diáspora. Identidades e mediações culturais. Tradução de Adelaine Resende, Ana Escoteguy, Cláudia Alvares, Francisco Rüdiger e Sayonara Amaral. Belo Horizonte: EDUFMG, 2003.

HARRIS, James E. "A diáspora africana no antigo e no novo mundo". História Geral da África V. África do século VI ao VIII. Capítulo 5. Brasília; São Carlos: UNESCO; EDUFSCar, 2010.

MARAIRE, J. Nozipo. Zenzele: Uma carta para minha filha. Tradução de Joana Angélica d'Ávila Melo. São Paulo: Mandarim, 1996.

MARECHERA, Dambudzo. House of hunger. London: Heinneman Education Books, 1993.

SELIGMANN-SILVA, Márcio. "Narrar o trauma. A questão dos testemunhos de catástrofes históricas". Revista Psiquiatria Clínica, Rio de Janeiro, v. 20, n. 1, p. 65-82, 2008.

SONTAG, Susan. A doença como metáfora. Tradução de Márcio Ramalho. Rio de Janeiro: Graal, 1984.

SONTAG, Susan. A AIDS como metáfora. Tradução de Paulo Henriques Britto. São Paulo: Schwarcs Ltda., 1989.

Larissa da Silva Lisboa Souza (lari.lisboa@gmail.com) é doutoranda do Programa de Estudos Comparados de Literaturas de Língua Portuguesa da Universidade de São Paulo (USP) e tem desenvolvido pesquisas relacionadas às literaturas de autoria feminina dos países africanos de língua portuguesa e do Zimbábue.

\section{COMO CITAR ESSE ARTIGO DE ACORDO COM AS NORMAS DA REVISTA}

SOUZA, Larissa da Silva Lisboa. "Narrar o trauma nas diásporas: Metáforas da doença nas literaturas de autoria feminina do Zimbábue". Revista Estudos Feministas, Florianópolis, v. 27, n. 1, e58984, 2019.

\section{CONTRIBUIÇÃO DE AUTORIA}

Concepção, coleta e análise de dados, elaboração do manuscrito e redação.

\section{FINANCIAMENTO}

\section{CAPES (Bolsa de Doutorado)}

\footnotetext{
${ }_{9}^{9}$ Refiro-me ao livro Império (2001), de Antonio Negri e Michael Hardt.
} 
LARISSA DA SILVA LISBOA SOUZA

\section{CONSENTIMENTO DE USO DE IMAGEM}

Não se aplica

APROVAÇÃO DE COMITÊ DE ÉTICA EM PESQUISA

Não se aplica

\section{CONFLITO DE INTERESSES}

Não se aplica

\section{LICENÇA DE USO}

Este artigo está licenciado sob a Licença Creative Commons CC-BY. Com essa licença você pode compartilhar, adaptar, criar para qualquer fim, desde que atribua a autoria da obra.

\section{HISTÓRICO}

Recebido em 03/09/2018

Aprovado em 07/09/2018 